\title{
Axillary Budbreak in a Cut Rose Crop as Influenced by Light Intensity and Red:far-red Ratio at Bud Level
}

\author{
A. Maaike Wubs ${ }^{1}$ \\ Horticultural Supply Chains, Wageningen University, P.O. Box 630, 6700 AP Wageningen, \\ The Netherlands; and Centre for Crop Systems Analysis, P.O. Box 430, 6700 AK Wageningen, \\ The Netherlands \\ Ep Heuvelink ${ }^{3}$ \\ Horticultural Supply Chains, Wageningen University, P.O. Box 630, 6700 AP Wageningen, \\ The Netherlands
}

Leo F.M. Marcelis

Wageningen UR Greenhouse Horticulture, P.O. Box 644, 6700 AP Wageningen, The Netherlands; and Horticultural Supply Chains, Wageningen University, P.O. Box 630, 6700 AP Wageningen, The Netherlands

Gerhard H. Buck-Sorlin ${ }^{2}$ and Jan Vos

Centre for Crop Systems Analysis, P.O. Box 430, 6700 AK Wageningen, The Netherlands

AdDitional INDEX wORDs. correlative inhibition, light emitting diodes, light spectrum, Rosa $\times$ hybrida

\begin{abstract}
When flower-bearing shoots in cut rose (Rosa $\times$ hybrida) are harvested, a varying number of repressed axillary buds on the shoot remainder start to grow into new shoots (budbreak). Earlier experiments indicated that light reaching the bud affected the number of budbreaks. In all these studies, whole plants were illuminated with different light intensities or light spectra. The aim of this article is to disentangle the effects of light intensity and light spectrum, in this case red:far-red ratio, at the level of the buds on budbreak in a rose crop. Three experiments were conducted in which light intensity and red:far-red ratio at the level of the buds were independently varied, whereas intensity and red:far-red ratio of incident light on the crop were not changed. Light intensity and red:far-red ratio at the position of the buds were quantified and related to budbreak on the shoot remainders. Removal of vertical shoots increased light intensity and red:far-red ratio as well as budbreak (1.9 budbreaks per shoot remainder compared with 0.4 budbreaks when five vertical shoots were present). No vertical shoots and red light-absorbing shading paper over the plant base mimicked the effect of vertical shoots with respect to light intensity and red:far-red ratio, but budbreak (1.0 budbreaks) was intermediate compared with treatments with and without shoots. This suggested that the presence of shoots exerts an inhibiting effect on budbreak through both effects on light at the bud and correlative inhibition. When plants had no vertical shoots and light intensity and red:far-red ratio at bud level were changed by neutral and red light-absorbing shading paper, there was a positive effect of light intensity on budbreak (0.3 more budbreaks per shoot remainder) and no effect of red:far-red ratio. Combinations of high and low light intensity with high and low red:far-red ratio on axillary buds showed that there was a positive effect of light intensity on budbreak ( 0.5 more budbreaks per shoot remainder) and no effect of red:far-red ratio. Our study reveals that when light intensity and red:far-red ratio received by the plant are similar but differ at bud level, budbreak was affected by light intensity and not by red:far-red ratio.
\end{abstract}

In cut rose crops, harvest of a mature shoot triggers axillary buds on the remainder of the shoot to grow. This budbreak is an important event in a cut rose crop because it is one of the factors

Received for publication 30 July 2013. Accepted for publication 19 Dec. 2013. This research was supported by the Dutch Technology Foundation STW-NWO (project 07435), which is the Technology Programme of the Ministry of Economic Affairs, and by the Product Board for Horticulture (project PT 13098).

We thank Gerard Brouwer, Ans Hofman, and Jos Kanne for their assistance in the experiments. We are grateful to the personnel of Unifarm for managing the plants and the climate. Members of the STW users committee are thanked for their advice about crop management.

${ }^{1}$ Current address: Biometris, Wageningen University and Research Centre, P.O. Box 100, 6700 AC Wageningen, The Netherlands.

${ }^{2}$ Current address: Institute National d'Horticulture et de Paysage, AGROCAMPUS OUEST Centre d'Angers, 2 rue André Le Nôtre, 49045 Angers cedex 01, France.

${ }^{3}$ Corresponding author. E-mail: ep.heuvelink@wur.nl. determining the number of harvestable shoots, next to the formation of blind shoots, i.e., shoots with an aborted flower bud (De Hoog, 2001). However, the number of broken buds is variable: a plant has several axillary buds, which potentially form a shoot, but not all of them do. As discussed by Wubs et al. (2013), shoot removal (harvest) not only removes apical dominance and correlative inhibition, but also leads to 1) increased light intensity reaching the axillary bud; and 2) changed spectrum of light reaching the bud (particularly a higher red:far-red ratio); and 3) changed source:sink ratio (i.e., the ratio between supply and demand of assimilates). Furthermore, the degree of budbreak on a shoot remainder is also influenced by the correlative inhibition exerted by other shoots on the plant (Wubs et al., 2013; Zieslin and Halevy, 1976). Wubs et al. (2013) concluded that after removal of a mature shoot, light reaching the axillary buds is an important factor explaining budbreak on the shoot remainder. However, 
those experiments could not completely discriminate between the effect of light intensity and light spectrum. Comparing between rose crops illuminated with fluorescent lamps [F (no far-red light)] and a mixture of fluorescent and incandescent light $\{\mathrm{F}+\mathrm{I}[\mathrm{red}$ :far-red ratio 0.64 , both treatments having equal amount of photosynthetic active radiation $(P A R)]\}$, Mor and Halevy (1984) found less budbreak of the lowest positioned bud on a shoot remainder under F+I compared with F. Similar spectral results were found in other studies on roses (Zieslin and Mor, 1990). Also in other plant species, light level and spectrum affect budbreak of plants [e.g., Arabidopsis thaliana (Finlayson et al., 2010; Su et al., 2011), Poaceae species (Belesky et al., 2011; Evers et al., 2006)], and ornamental crops (Mata and Botto, 2011), but the effects are not present in all plant species (e.g., Crotser et al., 2003; Kawamura and Takeda, 2002). Mor and Halevy (1984) suggested that the inhibitory effect of shoots on axillary budbreak is related to the low red:far-red ratio reaching the buds rather than to low light intensity. However, in several studies, it was found that budbreak increased when rose plants are grown at higher light levels, as reviewed by Zieslin and Mor (1990). In all these studies, whole plants were illuminated with different light levels or light spectra. Girault et al. (2008), in contrast, investigated the effects of light on the bud and found that both light intensity and light spectrum affected budbreak in simple rose systems consisting of a rooted stem with three nodes without leaves. This study suggested that the bud itself is the active site for light-mediated cues affecting budbreak.

In many greenhouse crops located at higher geographical latitudes, supplemental lighting is often used from fall to spring to enhance plant growth and to obtain year-round high production and good quality. With the introduction of lightemitting diodes (LEDs) as a light source, growers can choose to light the crop with different light spectra and to position the light source within the canopy (Mitchell, 2012; Trouwborst et al., 2010). In The Netherlands some rose growers have already installed LEDs inside the canopy. As a result of these developments, the question whether light level and/or light spectrum at the bud level affects budbreak is getting even more relevant.

The goal of this article is to disentangle the effect of light intensity and light spectrum at the bud level on axillary budbreak in a cut rose crop after the harvest of a shoot. Following the suggestion of Mor and Halevy (1984), we tested the hypothesis that axillary budbreak is inhibited by low red:far-red ratio reaching the buds rather than by low light intensity. Three experiments were conducted in which light spectrum and red:farred ratio at the bud level were independently varied. In each experiment, light intensity and red:far-red ratio at the bud level were quantified and related to budbreak. In contrast to Mor and Halevy (1984), light intensity and light spectrum on the crop were the same for all treatments.

\section{Materials and Methods}

All experiments were executed in the same rose crop, Rosa $\times$ hybrida cv. Akito. The crop was grown in a compartment $(12 \times 12 \mathrm{~m})$ of a multispan Venlo-type glasshouse in Wageningen, The Netherlands (lat. $52^{\circ} \mathrm{N}$ ). Plants were grown on mineral wool (rockwool) cubes $[7 \times 7 \times 7 \mathrm{~cm}$ (Rockwool Delta; Grodan, Roermond, The Netherlands)] positioned on rockwool slabs (Grodan) in double rows $(0.25 \mathrm{~m}$ between centers and path width of $1.20 \mathrm{~m}$ ) with $0.20-\mathrm{m}$ distance within the rows, resulting in a plant density of 6.5 plants $/ \mathrm{m}^{2}$. The crop was established in Spring 2008 from single node cuttings bearing a shoot. The experiments were conducted in the second half of 2009 and the first half of 2010. Between two successive experiments, the crop underwent several reset flushes (a flush is defined as the simultaneous harvest of shoots from all plants), during which it could recover from the previous experiment and the same architecture could be established in all plants.

Supplemental light was provided by high-pressure sodium lamps (600 W; Philips, Eindhoven, The Netherlands), which provided $150 \mu \mathrm{mol} \cdot \mathrm{m}^{-2} \cdot \mathrm{s}^{-1}$ at crop level. Lamps were switched on between 0000 and 2000 HR (until 15 Dec. 2009) and between 0000 and $1800 \mathrm{HR}$ (after 15 Dec. 2009, change is the result of local legislation) when outside global radiation was below $150 \mathrm{~W} \cdot \mathrm{m}^{-2}$ and switched off when this radiation exceeded $250 \mathrm{~W} \cdot \mathrm{m}^{-2}$. Realized light intensity (natural light and supplemental light) above the canopy was estimated from outside radiation and recordings of supplemental lighting. Heating set points were $17.5^{\circ} \mathrm{C}$ during the night and $21.0^{\circ} \mathrm{C}$ during the day. Realized climate conditions per experiment are given in Table 1. Water and nutrients $\left[0.17 \mathrm{~g} \cdot \mathrm{L}^{-1}\right.$ nitrogen, $0.04 \mathrm{~g} \cdot \mathrm{L}^{-1}$ phosphorus, $0.18 \mathrm{~g} \cdot \mathrm{L}^{-1}$ potassium (Substrafeed E1; Yara Benelux, Vlaardingen, The Netherlands)] were supplied through a drip system (one dripper per plant).

In all experiments, light intensity and red:far-red ratio at the bud level (i.e., low in the canopy, at the level of the shoot remainder on which budbreak was observed) were measured once or twice during the experiment. Light intensity was measured with a point sensor (LI-250A quantum sensor; LICOR Biosciences, Lincoln, NE) or a line sensor (LI-191; LICOR). Red:far-red ratio was measured with a 660/730-nm sensor (660/730; Skye Instruments, Llandrindod Wells,

Table 1. Photosynthetically active radiation, temperature, relative humidity (daily means), and $\mathrm{CO}_{2}$ concentration (mean during the light phase) in the greenhouse during the three experiments (2009-10) in which the effect of light intensity and red:far-red ratio at the level of the buds on axillary budbreak of Rosa $\times$ hybrida $\mathrm{cv}$. Akito was observed.

\begin{tabular}{llcccc}
\hline Expt. & \multicolumn{1}{c}{ Period } & $\begin{array}{c}P A R^{\mathrm{z}} \\
{\left[\mathrm{mean} \pm \mathrm{SD}\left(\mathrm{mol} \cdot \mathrm{m}^{-2} \cdot \mathrm{d}^{-1}\right)\right]}\end{array}$ & $\begin{array}{c}\text { Temp } \\
{\left[\mathrm{mean} \pm \mathrm{SD}\left({ }^{\circ} \mathrm{C}\right)\right]}\end{array}$ & $\begin{array}{c}\text { Relative humidity } \\
{[\mathrm{mean} \pm \mathrm{SD}(\%)]}\end{array}$ & $\begin{array}{c}\mathrm{CO}_{2} \text { concn }^{\mathrm{y}} \\
{\left[\mathrm{mean} \pm \mathrm{SD}\left(\mu \mathrm{L} \cdot \mathrm{L}^{-1}\right)\right]}\end{array}$ \\
\hline I & 21 Sept. to 5 Oct. & $12.9 \pm 1.1$ & $21.2 \pm 0.6$ & $66.9 \pm 2.5$ & $459 \pm 20$ \\
II & 4 to 17 Nov. & $11.2 \pm 0.3$ & $19.0 \pm 0.3$ & $73.5 \pm 2.3$ & $476 \pm 17$ \\
III & 13 to 27 Jan. & $10.4 \pm 1.0$ & $18.1 \pm 0.7$ & $81.8 \pm 2.8$ & $523 \pm 16$ \\
\hline
\end{tabular}

${ }^{\mathrm{z}}$ Radiation is derived from outside measurements of global radiation, transmission of the greenhouse (60\%), fraction PAR in global radiation (0.48) and hours that assimilation lights were switched on.

${ }^{\mathrm{y}} \mathrm{For}$ the $\mathrm{CO}_{2}$ concentration, only values during the period with light are taken (20 h in Expts. I and II, $18 \mathrm{~h}$ in Expt. III).

$P A R=$ photosynthetically active radiation. 
U.K.). All measurements were done around midday (1100 to $1400 \mathrm{HR})$.

In all experiments, budbreak was determined at the end of the experiment. A bud was defined as broken when leaves protruding from the scales measured more than $15 \mathrm{~mm}$.

Expt. I: Manipulating Light intensity AND Light SPECTRUM BY VARYING THE NUMBER OF SHOOTS, APPLICATION OF CREPE PAPER, AND REMOVAL OF LEAVES. Six vertical shoots and three bent shoots per plant were present before the experiment started (De Hoog, 2001). The experiment started when the flower buds from the vertical shoots were visible (shoots were $\approx 3$ weeks old). One vertical shoot per plant was cut to $1.5 \mathrm{~cm}$ from its base. This was the shoot remainder on which budbreak was monitored. Leaves were removed from this shoot remainder. Four treatments were imposed: no vertical shoots on the plant; five vertical shoots per plant; no vertical shoots and red light-absorbing shading paper, which decreased the light intensity and lowered the red:far-red ratio; and five vertical shoots per plant, from which the unfolded leaves were removed.

For the treatments without vertical shoots, these were removed by cutting them at their base. The red light-absorbing shading paper consisted of two layers of green crepe paper. It only covered the plant base (plant part above the rockwool slabs) and not the bent shoots, so the source strength of the plant was unaffected. The paper was renewed after $4 \mathrm{~d}$. Removal of the unfolded (mature) leaves was meant to increase the light intensity as well as the red:far-red ratio on the buds while maintaining apical dominance. New mature leaves were removed several times during the experiment.

The experiment was set up as a complete randomized block design with three blocks and four plots per block. Each plot consisted of 15 plants. The experiment was conducted in Sept. and Oct. 2009. Budbreak was determined $14 \mathrm{~d}$ after initiation of the treatments; 2 and $8 \mathrm{~d}$ after the start of the experiment, light intensity and red-far red ratio were measured with the LI-191 line quantum sensor and the 660/730-nm Skye sensor, respectively. The red-far red ratio at bud level was measured at three positions per plot. At both days, it was cloudy, and the lamps were on during the measurements on Day 8.

EXPT. II: MANIPULATING LIGHT INTENSITY AND RED:FAR-RED RATIO BY APPLICATION OF SHADING PAPER. Five vertical shoots and two bent shoots per plant were present before the experiment started. At the start of the experiment, two vertical shoots per plant were cut off $1.5 \mathrm{~cm}$ above their base. These were the shoot remainders used for the observation of budbreak. Leaves and stipules were removed from these shoot remainders. Other vertical shoots were cut off at their base. Light intensity and spectrum at bud level were varied in four treatments: high light intensity and high red:far-red ratio (control); intermediate light intensity and high red:far-red ratio, created by thin neutral shading paper; low light intensity and high red:far-red ratio, created by thick neutral shading paper; and low light intensity and low red:far-red ratio, created by red light-absorbing shading paper.

Different light intensities and red:far-red ratios at bud level were created by different colors and layers of crepe paper over the base of the plant. Thin neutral shading paper consisted of one layer of white crepe paper, thick neutral shading paper of two layers of white crepe paper and one layer of gray crepe paper, and red-absorbing shading paper consisted of two layers of green crepe paper.
The experiment was set up as a complete randomized block design with three blocks and four plots per block. Each plot consisted of 13 to 14 plants. Budbreak was scored $13 \mathrm{~d}$ after the start of the treatments.

The experiment was conducted in the first half of Nov. 2009. Light intensity and red:far-red ratio at bud level were measured 2 and $7 \mathrm{~d}$ after the start of the experiment with the LI-250A point quantum sensor and the 660/730-nm Skye sensor, respectively, at three positions per plot. Weather was cloudy with little natural radiation and assimilation light was switched on.

EXPT. III: MANIPULATING LIGHT INTENSITY AND RED:FAR-RED RATIO BY APPLICATION OF NEUTRAL SHADING PAPER AND FAR-RED LEDs. Five vertical shoots and three bent shoots per plant were present before the experiment started. At the start of the experiment, two vertical shoots per plant were cut off $0.5 \mathrm{~cm}$ above the lowest node, at least $1.5 \mathrm{~cm}$ from the shoot base. These shoot remainders were used for observation of budbreak. Other vertical shoots were cut $1 \mathrm{~cm}$ above the shoot base. All leaves from the plant base were removed. Light intensity and red:far-red ratio at bud level were independently varied in four treatments: high light intensity and high red:far-red ratio (control); low light intensity and high red:far-red ratio, created by neutral shading paper over the plant bases; high light intensity and low red:far-red ratio, created by far-red LEDs above the plants; and low light intensity and low red:far-red ratio, created by neutral shading paper over the plant bases and far-red LEDs above the plants.

Neutral shading paper was gray crepe paper, which was replaced after 1 week. At that time also the newly sprouting shoots on other shoot remainders were removed.

Far-red LEDs $(10 \mathrm{~W}$, GreenPower LED module HF far red; Philips) were positioned $\approx 50 \mathrm{~cm}$ above the rockwool slabs. Distance between the LEDs was $10 \mathrm{~cm}$. They provided a far-red light intensity of $15 \mu \mathrm{mol} \cdot \mathrm{m}^{-2} \cdot \mathrm{s}^{-1}(730$ to $740 \mathrm{~nm})$ at the top of the crop (measured with spectroradiometer). The LEDs were attached to a frame hanging from the ceiling of the greenhouse; a row of LEDs was positioned above the center of a plant row. In treatments without LEDs, a similar frame without LEDs was positioned above the plots (see Fig. 1 for visualization).

The experiment was set up as a complete randomized block design with three blocks and four plots per block. Each plot consisted of 15 plants. Budbreak was observed $14 \mathrm{~d}$ after the initiation of the experiments.

The experiment was conducted in Jan. 2010. On Day 6 of the experiment, light intensity and red:far-red ratio at bud level were measured at two positions per plot with the LI-COR quantum sensor, LI-250A point quantum sensor and the 660/ 730 Skye sensor, respectively. Weather was cloudy with little natural radiation and assimilation light was switched on.

Statistical analysis. Budbreak was expressed per shoot remainder, which was the average of one (Expt. I) or two shoot remainders per plant (Expts. II and III). Treatment means per plot were used in the analysis $(n=3$ for each treatment). Light intensity and red:far-red measurements were averaged per plot and then over the 2 measurement days (if applicable) before analysis. PAR measurements were ln-transformed to obtain equal variances for the treatments. Differences between the treatments in budbreak, light intensity, and red:far-red ratio were tested using one-way analysis of variance in Expts. I and II and two-way analysis of variance in Expt. III [factors being light intensity (high and low) and red:far-red ratio (high and low)]. A block effect was included in the statistical model. 
Differences between treatments were tested using Tukey's honest significant difference test. Analyses were done in GenStat Version 14 (VSN International, Hemel Hempstead, U.K.).

The mean daily $P A R$ integral over the shoot remainders was calculated from the outside $P A R$, the light transmissivity of the

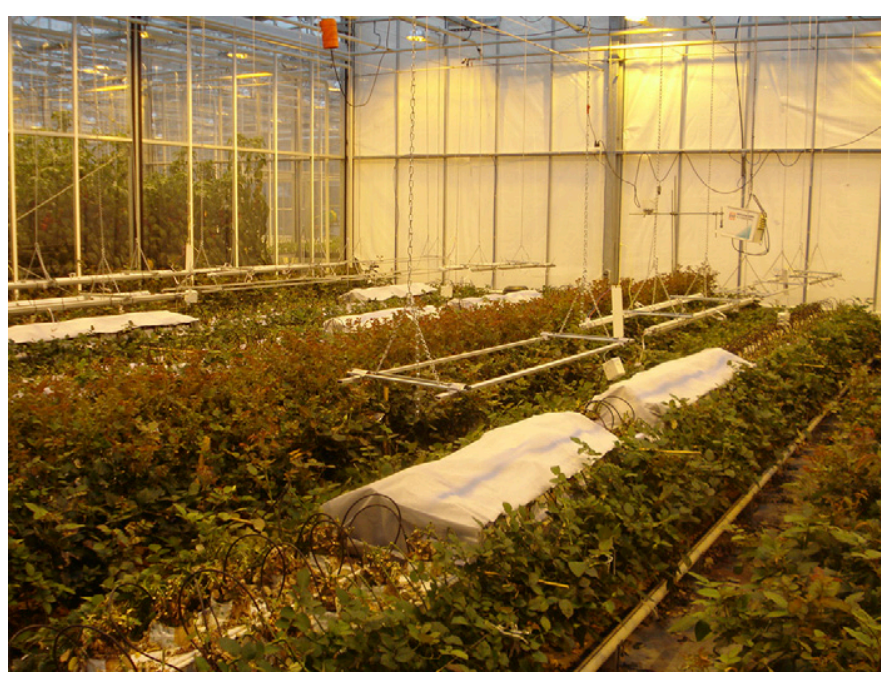

Fig. 1. On-site picture of Expt. III, in which the effect of high and low light intensity and high and low red:far-red ratio at the level of the bud on axillary budbreak in Rosa $\times$ hybrida cv. Akito was investigated. Buds were positioned on shoot remainders, resulting from the harvest of mature shoots. Frames hold the light-emitting diodes that reduce the red:far-red ratio; crepe paper reduces light level at the axillary buds to $10 \%$ of the ambient light level. Leaves from the plant base (part under the crepe paper) were removed. greenhouse $(60 \%)$, the number of hours that the lamps were switched on, and the ratio of the instantaneous measurement of photosynthetic photon fluxes at bud level of the treatment and of the standard. For conversion of outside radiation $\left(\mathrm{W} \cdot \mathrm{m}^{-2}\right)$ to $\mu \mathrm{mol} \cdot \mathrm{m}^{-2} \cdot \mathrm{s}^{-1}$, a factor of 4.6 (Langhans and Tibbitts, 1997) was used.

\section{Results}

LIGHT INTENSITY AND RED:FAR-RED RATIO. Light intensity and red:far-red ratio at the bud level differed significantly between the treatments in Expt. I $[P<0.001$ for all variables (Table 2)]. Light intensity at the bud level under five shoots was $9 \%$ of the light intensity without shoots present (Table 2). Red:far-red ratio under five shoots was reduced to $20 \%$ of the red:far-red ratio without shoots (Table 2). Red light-absorbing shading paper over the plant bases decreased light intensity and red:farred ratio at the level of the bud to values similar to or even lower than in the treatment with five shoots per plant (Table 2). Removal of leaves from the vertical shoots increased light intensity at the bud level compared with the treatment where shoots were present, but it was not as high as when no shoots were present (Table 2). Red:far-red ratio at bud level when leaves were removed from vertical shoots were similar to the treatment where vertical shoots were removed (Table 2).

Light intensity at the bud level was significantly affected by the treatments in Expt. II $[P<0.001$ (Table 2)]. Thin neutral shading paper decreased light intensity to $61 \%$ of the control. Light intensity was comparable between plant bases covered with thick neutral shading paper and red light-absorbing shading paper and was $11 \%$ to $13 \%$ of the control (Table 2 ).

Table 2. Measured instantaneous light intensity and red:far-red ratio and derived daily integral of $P A R$ at bud level in three experiments in which the effect of light intensity and red:far-red ratio at the bud level on axillary budbreak of Rosa $\times$ hybrida cv. Akito was observed. ${ }^{\mathrm{z}}$

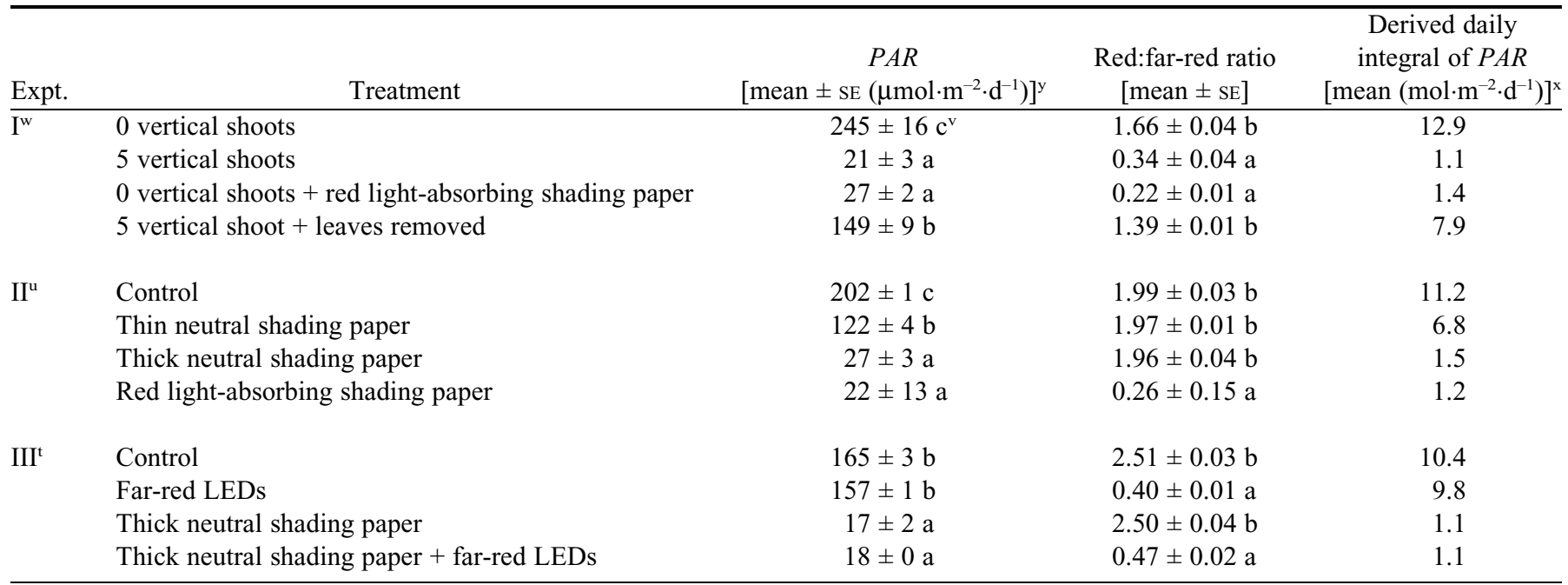

${ }^{\mathrm{z}}$ Mean and SE (between brackets) are given for the measured variables. A varying number of vertical shoots was present in Expt. I. In Expts. II and III, no vertical shoots were present. There were two (Expt. II) and three (Expts. I and III) bent shoots per plant.

${ }^{\mathrm{y}}$ Light intensity was ln-transformed for analysis.

${ }^{x}$ Mean daily $P A R$ integral for each treatment was derived from the mean daily $P A R$ integral and the fraction light at the buds compared with control treatments; this fraction is derived from instantaneous light measurements.

wLight intensity and red:far-red ratio were measured on Days 2 and 8; averages over these $2 \mathrm{~d}$ are given.

'Different letters within an experiment indicate significant difference between the treatments with Tukey's honest significant difference test $(\mathrm{n}=3, \alpha=0.05)$.

uLight intensity and red:far-red ratio were measured on Days 2 and 7; averages over these $2 \mathrm{~d}$ are given.

tLight intensity and red:far-red ratio were measured on Day 6.

$P A R=$ photosynthetically active radiation; LEDs $=$ light-emitting diodes. 
However, red:far-red ratio differed between these latter two treatments, because only the red light-absorbing shading paper affected red:far-red ratio $[P<0.001$ (Table 2)].

Light intensity at the bud level was decreased by $\approx 90 \%$ by the neutral shading paper compared with the control $(P<0.001)$ in Expt. III, but red:far-red ratio was not decreased $[P=0.25$ (Table 2)]. Red:far-red ratio was only affected by the far-red LEDs $(P<0.001)$. There was no interaction between shading paper and LEDs on light intensity and red:far-red ratio $(P=0.28$ and 0.15 , respectively). The reduction of the red:far-red ratio in Expt. III by the far-red LEDs was less than by the red lightabsorbing shading paper in Expts. I and II.

Budbreak. In Expt. I, there were significant differences in budbreak between the treatments $[P<0.001$ (Fig. 2)]. Most buds broke when no shoots or shading paper were present, and the lowest number of budbreaks was observed when five vertical shoots were present. Removal of leaves from the five vertical shoots significantly increased budbreak compared with plants with five vertical shoots but resulted in lower budbreak than when no vertical shoots were present. Budbreak under red light-absorbing shading paper was not significantly different from budbreak when leaves were removed from the vertical shoots.

In Expt. II, a significant effect of the shading paper on budbreak was found $(P=0.018)$, but the only significant difference was between the control and the treatment with low light intensity and low red:far-red ratio (red light-absorbing shading paper). Regression analysis on the number of broken buds against the mean daily $P A R$ integral for treatments with the same red:far-red ratio showed a significant positive correlation $[P=0.04$ (Fig. 3A)], although pairwise comparisons of budbreak at the different light levels were not significant. In the same experiment, budbreak for treatments with the same mean daily $P A R$ integral but different red:far-red ratios did not differ $[P=0.30$ (Fig. 4A) $]$.

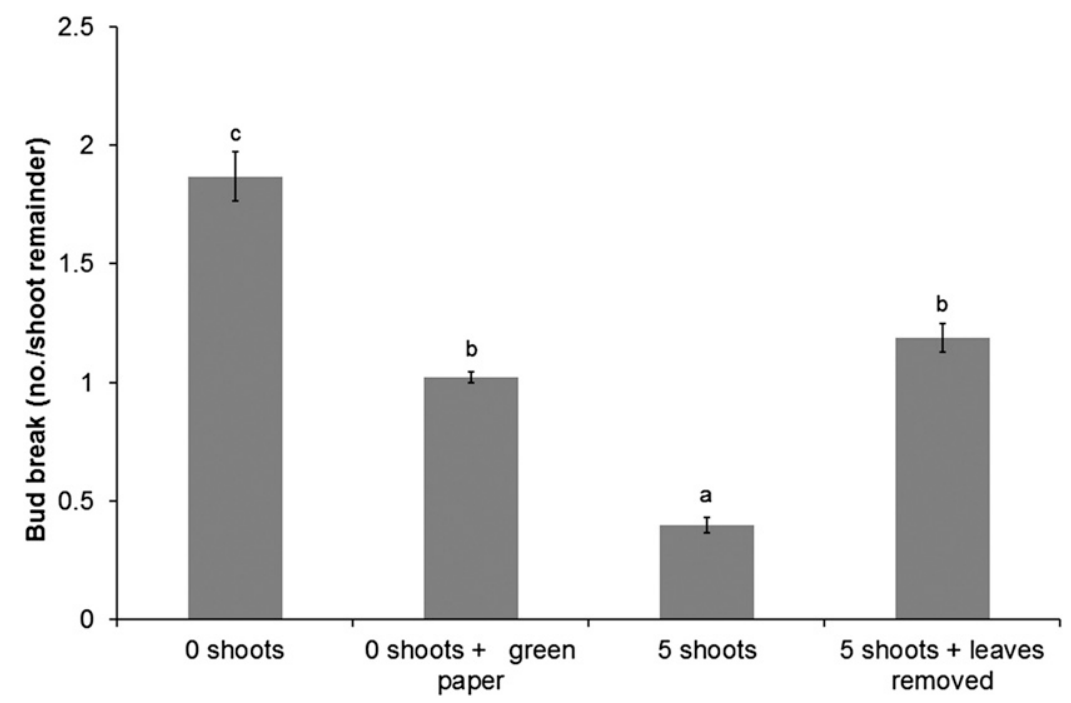

Fig. 2. Axillary budbreak in Expt. I, in which light intensity and red:far-red ratio at the levels of the buds on budbreak in Rosa $\times$ hybrida cv. Akito were varied by the number of vertical shoots (zero and five shoots), removal of shoots combined with red light-absorbing paper over the plant base (zero shoots + red light-absorbing paper), and removal of leaves from vertical shoots (five shoots + leaves removed). Budbreak was observed on shoot remainders. Shoot remainders were created by harvesting mature shoots. All plants had three bent shoots. Error bars represent sEMs; different letters indicate significant differences between treatments obtained with Tukey's honest significant difference test $(\mathrm{n}=3, \alpha=0.05)$.
In Expt. III, a decrease in mean daily $P A R$ integral at the same red:far-red ratio significantly $(P=0.003)$ decreased budbreak (Fig. 3B-C). A decreased red:far-red ratio at the same mean daily $P A R$ integral did not affect budbreak $[P=0.35$ (Fig. 4B-C)]. There was no interaction $(P=0.93)$ between the effect of mean daily $P A R$ integral (shading paper) and red:farred ratio (far-red LEDs) on budbreak.

\section{Discussion}

In rose crops, shoots are harvested when the sepals of the flower bud start to open, revealing the color of the petals. On the basal part of the shoot that is left (the shoot remainder), axillary buds break and develop into the next harvestable flower shoots. A previous study (Wubs et al., 2013) indicated that the degree of budbreak on shoot remainders positively responded to more light in combination with higher red:far-red ratio received by the buds, but effects of light intensity and light spectrum could not be separated. The experiments in this study were set up to disentangle the effects of light intensity and red:far-red ratio reaching the axillary buds in a rose crop, trying to determine whether one or the other is more important for triggering axillary budbreak of a crop or that both are equally important.

The results of Expts. II and III showed a small positive effect of light intensity at bud level on budbreak and no effect of red:far-red ratio at bud level on budbreak. Mor and Halevy (1984) attributed decreased budbreak under illumination with a mixture of fluorescent and incandescent light $(\mathrm{F}+\mathrm{I})$ as compared with only fluorescent light ( $\mathrm{F}$, containing no far-red radiation) with the lower red:far-red ratio in the $\mathrm{F}+\mathrm{I}$ light environment (0.64). In their case, the whole crop was subjected to low red:far-red ratio, whereas in our study, only the shoot remainders experienced low red:far-red ratios. Also experiments with other plant species where effects of light spectrum on budbreak or branching were observed often changed light spectrum for the whole plant (e.g., Clifford et al., 2004; Crotser et al., 2003; Mata and Botto, 2011). Our research focused on the effect of light received by the bud, because light on the bud is necessary for the bud to break (Girault et al., 2008). Changing red:farred ratio affects the phytochrome status (Franklin and Whitelam, 2005). The contrast between the current findings (no effect of red:far-red at bud level on budbreak) to literature reporting decreased budbreak when the whole plant is subjected to low red:farred ratios might indicate that not only the phytochrome status of the bud and the adjacent stem is important for budbreak, but the phytochrome status of the whole plant. However, such a proposition needs testing in a dedicated factorial experiment in which the red:far-red ratio of the plant and the bud is varied independently. Furthermore, studies on the effects of light intensity on budbreak also changed light intensity on the whole plant (e.g., Mata and Botto, 2011; Schoellhorn et al., 1996; Su et al., 2011; Zieslin and Mor, 1990). Our study reveals that when light intensity and red:far-red ratio received by the plant are similar but differ at bud level, 

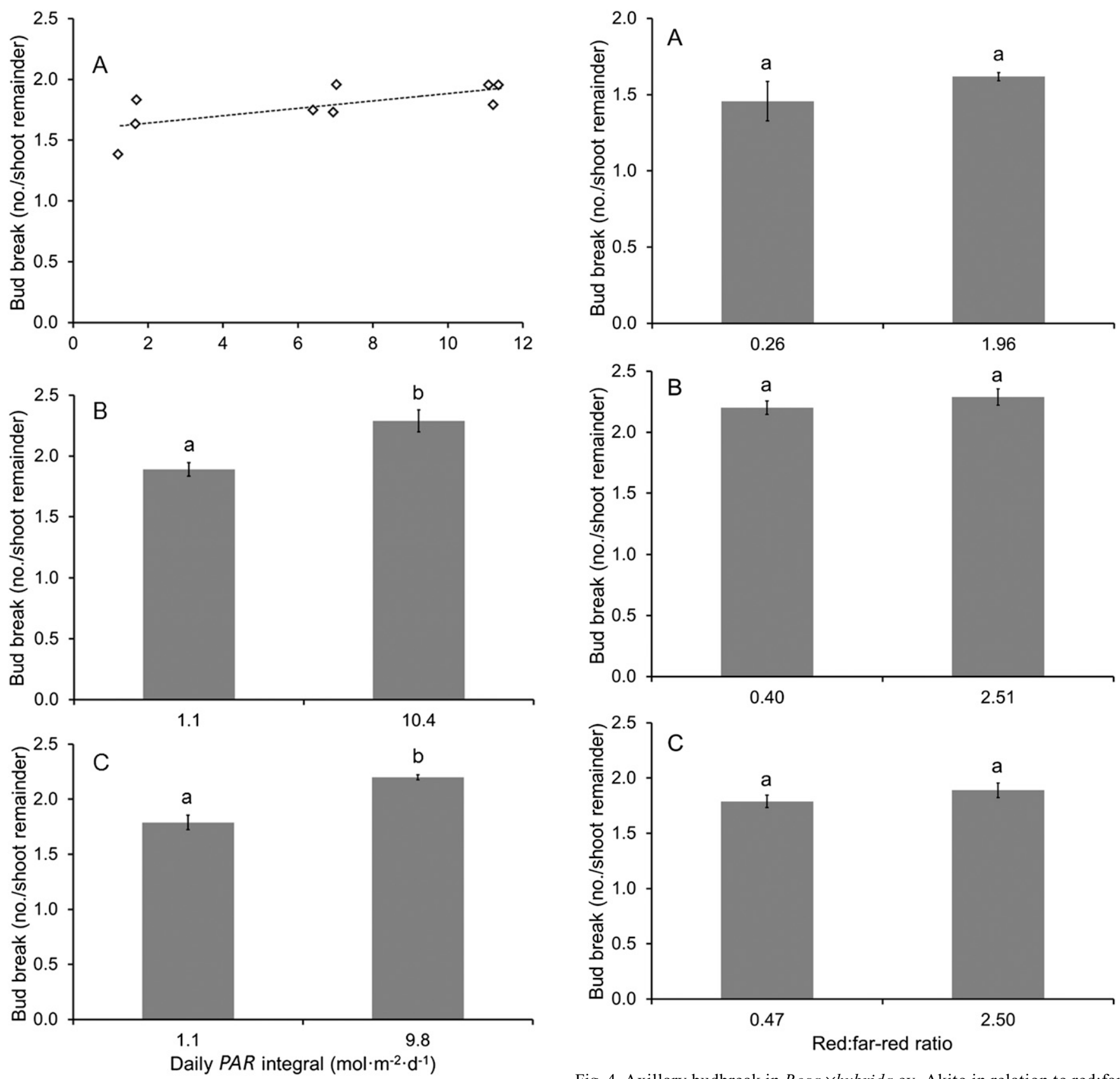

Fig. 3. Axillary budbreak in Rosa $\times$ hybrida cv. Akito in relation to mean daily photosynthetically active radiation $(P A R)$ integral at bud level for treatments with similar red:far-red ratio at bud level. (A) Expt. II, different mean daily $P A R$ integrals at high red:far-red ratio (1.96 to 1.99$)$; treatments created by different thickness of neutral shading paper; values for each replicate (block) are shown; regression showed a significant positive effect of mean daily $P A R$ integral on budbreak $(P=0.04)$. (B) Expt. III, low and high mean daily $P A R$ integrals at high red:far-red ratio (2.50 to 2.51$)$; low daily $P A R$ integral was created by neutral shading paper. (C) Expt. III, low and high mean daily $P A R$ integrals at low red:far-red ratio ( 0.40 to 0.47$)$; low red:far-red ratio was obtained with far-red light-emitting diodes; low mean daily $P A R$ integral by neutral shading paper. Budbreak was observed on shoot remainders. Shoot remainders were created by harvesting mature shoots. Plants in both experiments had no vertical shoots, and two and three bent shoots were present in Expts. II and III, respectively. Error bars represent SEMS; different letters indicate significant differences between treatments obtained with Tukey's honest significant difference test $(\mathrm{n}=3, \alpha=0.05)$.

Fig. 4. Axillary budbreak in Rosa $\times$ hybrida cv. Akito in relation to red:farred ratio at bud level for treatments with similar mean daily photosynthetically active radiation $(P A R)$ integral at bud level. (A) Expt. II, different red:far-red ratios at low mean daily $P A R$ integral $\left(1.2\right.$ to $\left.1.5 \mathrm{~mol} \cdot \mathrm{m}^{-2} \cdot \mathrm{d}^{-1}\right)$; treatments created by either neutral light-absorbing shading paper (high red:far-red ratio) or red light-absorbing shading paper (low red:far-red ratio). (B) Expt. III, low and high red:far-red ratio at high mean daily $P A R$ integral $\left(10 \mathrm{~mol} \cdot \mathrm{m}^{-2} \cdot \mathrm{d}^{-1}\right)$; low red:far-red ratio was created by far-red LEDs. (C) Expt. III, low and high red:far-red ratio at low mean daily $P A R$ integral $\left(1.1 \mathrm{~mol} \cdot \mathrm{m}^{-2} \cdot \mathrm{d}^{-1}\right)$; low mean daily $P A R$ integral was created by neutral shading paper; low red:far-red ratio by far-red LEDs. Budbreak was observed on shoot remainders. Shoot remainders were created by harvesting mature shoots. Plants in both experiments had no vertical shoots, and two and three bent shoots were present in Expts. II and III, respectively. Error bars represent SEMS; different letters indicate significant differences between treatments obtained with Tukey's honest significant difference test $(\mathrm{n}=3, \alpha=0.05)$. 
budbreak was positively affected by light intensity and not by red:far-red ratio.

Part of the treatments in the presented experiments aimed at changing the red:far-red ratio. This is only part of the light spectrum. Light spectrum is more completely quantified by the phytochrome stationary state [PSS (Sager et al., 1988)]. PSS was also calculated for the presented experiments. Which treatments differed from each other with respect to PSS was very similar to the differences between the treatments expressed in red:far-red ratio (data not shown). It has to be borne in mind that in general, and depending on the spectral composition of the light, expressing light quality in PSS or in red:far-red ratio may result in different conclusions; in such cases, PSS should be the preferred above red:far-red ratio as a measure to express spectral effects.

The red:far-red ratio at the end of the day is known to affect plant height (Lund et al., 2007; Maas and Bakx, 1995) and flower development (Maas and Bakx, 1995), although it did not affect budbreak (tillering) in Lolium perenne (Casal et al., 1990). Our red:far red treatments were always maintained during the day until sunset. In Expts. I and III, end-of-day red:far-red ratio was measured, but the difference between the treatments in end-of-day red:far-red ratio did not correspond to differences in budbreak (data not shown).

The results of Expt. I confirmed the role of correlative inhibition by the leaves (suppression of budbreak resulting from the presence of plant organs including but not limited to the shoot tip) as a determinant of budbreak in addition to exposure to light. Light intensity and red:far-red ratio were similar in the treatment with five shoots and the treatment without shoots with red light-absorbing shading paper over the plant base (Table 2), but budbreak was lower in the treatment with five shoots. This indicates that vertical shoots affected budbreak both through their effect on light conditions at the bud level and through correlative inhibition. Removal of shoots can also affect the source-sink balance of the crop. However, Wubs et al. (2013) showed that source-sink ratio was not unequivocally related to budbreak.

There was a considerable difference in budbreak between the experiments. Budbreak was higher in Expts. II and III than in Expt. I, whereas differences between the treatments were most pronounced in Expt. I. An explanation for the high overall level of budbreak in Expts. II and III might be the absence of correlative inhibition from vertical shoots. Correlative inhibition relates to suppression of budbreak through hormonal interactions of mainly auxin, cytokinins, and strigolactones (Domalgalska and Leyser, 2011). Another reason for the high overall level of budbreak in Expts. II and III might be the use of assimilation lamps (high-pressure sodium lamps). Assimilation lights increased the red:far-red ratio on the whole crop (see control treatments in Table 2). Apart from light, other climatic factors might have also affected budbreak, like air humidity (García Victoria et al., 2007) and temperature (Mattson and Lieth, 2007).

Because light intensity at the level of axillary buds down in the canopy stimulates budbreak, growers may install LED lamps as interlighting in the canopy. In fact, some growers in The Netherlands are already testing interlighting in roses. Furthermore, if growers want to stimulate budbreak, they may adapt pruning strategies to obtain a more open canopy, which allows more light penetrating to the axillary buds. Although the differences between the treatments at plant level are small, for a whole greenhouse, it would make a substantial increase in production if half of the plants would make an extra shoot as a result of increased light intensity at the buds.

In conclusion, when buds on shoot remainders, resulting from the harvest of mature shoots, were exposed to light of equal red:far-red ratios, there was a positive effect of light intensity at the bud level on budbreak. Conversely, under similar light intensities at bud level, red:far-red ratio at bud level had no effect on budbreak. Differences in budbreak when light conditions were similar and plant architecture was different implied that correlative inhibition modifies the effects of the light regime.

\section{Literature Cited}

Belesky, D.P., D.M. Burner, and J.M. Ruckle. 2011. Tiller production in cocksfoot (Dactylis glomerata) and tall fescue (Festuca arundinacea) growing along a light gradient. Grass Forage Sci. 66:370-380.

Casal, J.J., R.A. Sanchez, and D. Gibson. 1990. The significance of changes in the red/far-red ratio, associated with either neighbour plants or twilight, for tillering in Lolium mulitflorum Lam. New Phytol. 116:565-572.

Clifford, S.C., E.S. Runkle, F.A. Langton, A. Mead, S.A. Foster, S. Pearson, and R.D. Heins. 2004. Height control of poinsettia using photoselective filters. HortScience 39:383-387.

Crotser, M.P., W.W. Witt, and L.A. Spomer. 2003. Neutral density shading and far-red radiation influence black nightshade (Solanum nigrum) and eastern black nightshade (Solanum ptycanthum) growth. Weed Sci. 51:208-213.

De Hoog, J. 2001. Handbook for modern greenhouse rose cultivation. Applied Plant Research, Aalsmeer, The Netherlands.

Domalgalska, M.A. and O. Leyser. 2011. Signal integration in the control of shoot branching. Nat. Rev. Mol. Cell Biol. 12:211-221.

Evers, J.B., J. Vos, B. Andrieu, and P.C. Struik. 2006. Cessation of tillering in spring in relation to light interception and red/far-red ratio. Ann. Bot. (Lond.) 97:649-658.

Finlayson, S.A., S.R. Krishnareddy, T.H. Kebrom, and J.J. Casal. 2010. Phytochrome regulation of branching in Arabidopsis. Plant Physiol. 152:1914-1927.

Franklin, K.A. and G.C. Whitelam. 2005. Phytochromes and shadeavoidance responses in plants. Ann. Bot. (Lond.) 96:169-175.

García Victoria, N., B. Eveleens, and H.J. Van Telgen. 2007. Development of a phase dependent growth strategy for mobile rose cultivations systems. Acta Hort. 751:137-148.

Girault, T., V. Bergougnoux, D. Combes, J.D. Viemont, and N. Leduc. 2008. Light controls shoot meristem organogenic activity and leaf primordial growth during bud burst in Rosa sp. Plant Cell Environ. 31:1534-1544.

Kawamura, K. and H. Takeda. 2002. Light environment and crown architecture of two temperature Vaccinium species: Inherent growth rules versus degree of plasticity in light response. Can. J. Bot. 80:1063-1077.

Langhans, R.W. and T.W. Tibbitts. (eds.). 1997. Plant growth chamber handbook. North Central Regional Res. Publ. No. 340, Iowa Agr. Home Econ. Expt. Sta. Special Rpt. No. 99. Iowa State Univ., Ames, IA.

Lund, J.B., T.J. Blom, and J.M. Aaslyng. 2007. End-of-day lighting with different red/far-red ratios using light-emitting diodes affects plant growth of Chrysanthemum $\times$ morifolium Ramat. 'Coral Charm'. HortScience 42:1609-1611.

Maas, F.M. and E.J. Bakx. 1995. Effects of light on growth and flowering of Rosa hybrids 'Mercedes'. J. Amer. Soc. Hort. Sci. 120:571-576.

Mata, D.A. and J.F. Botto. 2011. Photoperiod, light, and temperature requirements to control plant architecture and flowering time in Salvia exserta. J. Hort. Sci. Biotechnol. 89:408-414.

Mattson, N.S. and J.H. Lieth. 2007. The effect of temperature on yearround development of rose shoots initiated using cutting or bending. Acta Hort. 751:121-128. 
Mitchell, C.A. 2012. Plant lighting in controlled environments for space and earth applications. Acta Hort. 956:23-36.

Mor, Y. and A.H. Halevy. 1984. Dual effect of light on flowering and sprouting of rose shoots. Physiol. Plant. 61:119-124.

Sager, J.C., W.O. Smith, J.L. Edwards, and K.L. Cyr. 1988. Photosynthetic efficiency and phytochrome photoequilibria determination using spectral data. Trans. Amer. Soc. Agr. Eng. 31:1882-1888.

Schoellhorn, R.K., J.E. Barrett, and T.A. Nell. 1996. Branching of chrysanthemum cultivars varies with season, temperature, and photosynthetic photon flux. HortScience 31:74-78.

Su, H., S.D. Abernathy, R.H. White, and S.A. Finlayson. 2011. Photosynthetic photon flux density and phytochrome interact to regulate branching in Arabidopsis. Plant Cell Environ. 34:1986-1998.
Trouwborst, G., J. Oosterkamp, S.W. Hogewoning, J. Harbinson, and W. Van Ieperen. 2010. The responses of light interception, photosynthesis and fruit yield of cucumber to LED-lighting within the canopy. Physiol. Plant. 138:289-300.

Wubs, A.M., E. Heuvelink, L.F.M. Marcelis, R.C.O. Okello, A. Shlyuykova, G.H. Buck-Sorlin, and J. Vos. 2013. Four hypotheses to explain axillary budbreak after removal of flower shoots in a cut rose crop. J. Amer. Soc. Hort. Sci. 138:243-252.

Zieslin, N. and A. Halevy. 1976. Components of axillary bud inhibition in rose plants. I. The effect of different plant parts (correlative inhibition). Bot. Gaz. 137:291-296.

Zieslin, N. and Y. Mor. 1990. Light on roses. A review. Sci. Hort. 43:1-14. 